\title{
Microscopical Examination: The Impact of Different lonising Radiation Doses Over Protective Clothing Used in the Operating Theatre
}

\author{
M. J. Abreu ${ }^{1^{*}}$, M. E. Cabeço Silva ${ }^{1}$, L.Schacher ${ }^{2}$ and D. Adolphe ${ }^{2}$ \\ ${ }^{1}$ Departamento de Engenharia Têxtil - Universidade do Minho \\ 4800-058 Guimarães - Portugal, \\ ${ }^{2}$ Ecole Nationale Supérieure des Industries Textiles de Mulhouse, 68093 Mulhouse Cedex - \\ France, E-mail: I.schacher@uha.fr; d.adolphe@uha.fr
}

Keywords: Ionising radiation, Protective clothing, Surgical gowns, Scanning Electron Microscope, Properties

\begin{abstract}
The goals to be pursued by this paper are to highlight the effect of different ionising radiation methods, considered low temperature sterilisation, over protective clothing (surgical gowns) used in the operating theatre through microscopical examination. In order to investigate the influence of the radiation on the properties of nonwoven-based surgical gowns, two types of radiation (gamma and electron beam radiation) were considered in this study. The Scanning Electron Microscope (SEM) is widely used in studies of polymers, although for this kind of nonwoven based structures, that goes through sterilisation treatments it isn't commonly used. So, this paper also intends to relate the results of the evaluation of comfort and barrier properties after irradiated at several doses in a range from 0 to $160 \mathrm{kGy}$.
\end{abstract}

\section{Introduction}

The surgical gown used in the operating theatre is considered as a non-active medical device and obey the Medical Device Directive 93/43/EEC. According to this Directive, surgical clothing, drapes and air suits are considered to be medical devices, whether they are reusable or single-use gowns and drapes. However at the same time, it is a protective clothing, because of the possible microbial contamination present during the operation. Laying the groundwork for this type of research, until know the manufacturers of surgical gowns generally specified the study of the properties from the material used before sterilisation, unknowing the changes that can appear after the sterilisation. A product that was designed successfully could after a sterilisation process be transformed in an unrecognisable piece of material. Nevertheless this sterilisation can induce some positive changes in their behaviour, and some of them could restrict their use for the defined applications. The study of surface degradation after the irradiation process at different doses is important, since the microscopic examination may indicate why the component degraded. The performance of the surgical gowns demands a balance between barrier and comfort properties. So, the problem of the optimisation of one fabric's property at the detriment of another could be explained by the miscroscopical analysis. It is unlikely that a comfortable garment could be totally resistant or impermeable to liquid penetration when rubbed or subjected to the pressures present during its "usual conditions of use". The only reasonable conclusion appeared to be a compromise between liquid resistance and air permeability for the sake of comfort.

\section{Purpose and Importance of Sterilisation}

The primary purpose of sterilising an item is to render it safe for use by destroying all living microscope organisms (EN 556). An object can never be almost, partially or practically sterilised: is it either sterilised or not sterilised. Even a few organisms invading the patient's body during a surgical procedure can reproduce rapidly and contribute to post-operative complications.

Corresponding author: josi@det.uminho.pt; elisabete@det.uminho.pt 